3.

\title{
Creative Communities
}

Shaping Process through Performance and Play

Lynn Parker \& Dayna Galloway

Transactions of the Digital Games Research Association

2017, Vol. 3, No. 2, pp. 57-87

ISSN 2328-9422

http://todigra.org

TEXT: Licensed under Creative Commons Attribution (CC BY-

NC- ND 2.5) http://creativecommons.org/licenses/by-nc- nd/2.5/

IMAGES: All images appearing in this work are property of the respective copyright owners, and are not released into the Creative Commons. The respective owners reserve all rights.

\section{ABSTRACT}

This paper studies the use of play as a method to unlock creativity and innovation within a community of practice (a group of individuals who share a common interest and who see value in interaction to enhance their understanding). An analysis of communities of practice and the value of play informs evaluation of two case studies exploring the development of communities of practice, one within the discipline of videogames and one which bridges performing arts and videogames. The case studies provide qualitative data from which the potential of play, as a method to inspire creativity and support the development of a potential 
community of practice, is recognised. Establishing trust, disruption of process through play and reflection are key steps proposed in a 'context provider's framework' for individuals or organisations to utilise in the design of activities to support creative process and innovation within a potential community of practice.

\section{Keywords}

Videogames, communities of practice, collaboration, play, performance, design process.

\section{INTRODUCTION}

Videogames and the performing arts are intrinsically linked by the notion of play. Flanagan (2009) identifies the performative nature of games, whereby a "negotiation of action" is required for play. Conversely, play is identifiable in the constructs of performance, where imagination, improvisation and physical expression make up a significant part of an actor, or indeed player's repertoire. The medium of videogames has selectively drawn from the cultural practices of film, music, dance and theatre, with clear parallels existing between the construction of game environments and set design or interactive art installations. In each instance a context for an experience is established, with forethought into how the audience can perceive, navigate and infer meaning from both the physical space and the action that is staged within it. Against this context, there are important questions about how best to share methods and experience across different communities of creative practice, and how such collaborative approaches might purposefully support the creation of innovative and creative works across a range of artistic disciplines.

The context of this research is characterised by the emergence of digital gaming as a cultural form that has grown from technological roots into the dominant entertainment form of the 21st century. As this medium 
continues to develop one can observe an increasing diversification and segmentation of audience and players as it seeks to find new modes to engage more sophisticated audiences and create meaningful experiences (Crecente, 2014, Jenkins, 2005). Parallel developments have seen the adoption of game-like practices in site-specific theatre and are concurrent with the growth in popularity of location-based gaming (Dixon, 2007, Kwastek, 2013, Wood, 2011).

Collaboration across disciplines is central to the creation of such digitally mediated experiences, and issues with working across discipline boundaries have been the focus of much academic enquiry within the creative industries (O’Grady, 2011; Shyba, 2007). Economic growth and policy formation have also been a focus of studies into the creative industries and the recognition and support of creative clusters (Ball, 2014; Chapain et al., 2010; Creative Scotland, 2014). The formation and development of a collaboration itself has, however, been less of a focus of academic research. This paper seeks to explore the process of developing creative communities, underpinned by the concepts of communities of practice, and proposes that play can be utilised as a method to foster and evolve creativity and innovation within communities of practice and across discipline-related boundaries. Within the context of this paper, a community of practice is defined as a group that is formed due to shared interest, but which develops into a culture of creativity, with a shared language, and shared basic assumptions that lead to the creation of knowledge and meaning (Wenger, 1998).

To explore the evolution of creative communities, firstly a foundation for understanding culture and communities of practice is formed, and the value of play is explored in relation to creative potential. Existing initiatives within creative communities such as the creative hub are examined to understand the use of play to trigger creative potential through disruption of conventions. This underpins case study analysis of two examples of the development of communities of practice; one within the field of videogames, and one that bridges performing arts and videogames. The case study experiences provide qualitative data from 
which play, as a method for developing a community of practice and unlocking creativity, is examined. The contribution of this paper is the proposition of a theoretical framework for use in the conception and design of events which aim to harness potential within communities of practice through enhancement (and reinvigoration) of creative process to enable innovation in the creation of digitally-mediated art and the emergence of novel outcomes.

\section{CULTURE AND COMMUNITIES OF PRACTICE}

Salen and Zimmerman (2004) present a common understanding of culture as the collective ideals, traditions and knowledge possessed by a group or society. Through examination of multiple definitions of culture, they identify three key elements - "what people think, what they do, and the material products they produce.” (p.508) Schein (2010) proposes that a group's culture can be explored at three levels and that the core assumptions that exist across a group play a significant role in the formation and adoption of specific beliefs and values, which in turn influence observable factors such as behaviour, structures and processes. Schein further asserts that a group can form dependencies on these underlying assumptions to maintain a solid grounding and a collective understanding of purpose. Challenging these assumptions and propositioning for change can provoke negative or defensive reactions, anxiety, and disengagement, all of which are counter-productive to the development of a creative community.

The assumptions that are prevalent within a culture can present limitations on conceptualisation and production process whereby initially successful ideals and methods of working become accepted as normal or best practice, and remain unchallenged. Such an occurrence can lead to the formation of collectively perceived constraints that diminish a team's ability to identify and explore alternative or innovative solutions. A process proposed by Norman (1998) identifies and embraces constraints, and pairs them with affordances to provide support for using unfamiliar objects or being in unfamiliar situations, whereby 
"affordances suggest the range of possibilities, constraints limit the number of alternatives" (p82). Norman classifies constraints into four distinct classes:

- Physical - limitations defined by space, size, and shape

- Semantic - limitations defined by meaning and purpose

- Cultural - limitations defined by acceptable behaviour and societal conventions

- Logical - limitations defined by natural connections and the logic of relationships.

These classifications of constraints have the potential to be broadly applied as a tool to analyse and deconstruct the development processes of creative teams and communities. For example, a game designer is confronted by all four of these classes when designing a game around a particular controller or input device. The process undertaken and the solutions established by the designer are shaped by the physical construction and size of the controller, its purpose as a handheld device, the culturally acceptable function of each trigger, and the logical and instinctive mappings of the directional buttons. The designer is operating within the context of a domain of knowledge, a concept that Csikszentmihalyi (1996) suggests is constituted of a particular set of methods, systems, rules and symbolic representation. When the rules of a domain are understood, a transformative and empowering experience can emerge that "expands the limitations of individuality and enlarges our sensitivity and ability to relate to the world.” (p. 37) The process of learning the skills and procedures of an additional domain can be a challenging activity requiring practice and commitment, and can be positively and negatively influenced by factors such as interventions from external bodies or the structure and accessibility of the knowledge.

The concept of a domain has also been adopted to describe the three core characteristics of a community of practice. According to Wenger et al. (2002) the domain establishes the identity of a community through 
knowledge, purpose, and meaning; that community exists as the social connections and relationships that supportively facilitate learning; and practice is the activities and items that the community undertakes, shares, and creates.

Communities of practice can exist in three states: potential, active and latent (Wenger, 1998). Potential communities are "possible communities among people who are related somehow, and who would gain from sharing and developing a practice together.” (p. 228) Active communities are at work, effectively negotiating participation and forming their own domain-specific history, whilst latent communities are those which no longer exist but inform and feed into the practice, language, knowledge and history of each of its former members. In understanding the make-up of a community of practice it is also important to note that they "are about content - about learning as a living experience of negotiating meaning - not about form.” (Wenger, 1998, p.228)

It is not possible to design a community of practice or to use these concepts as a device to bring individuals together. Instead the community must already exist in one of the three possible states and can only be "recognised, supported, encouraged and nurtured" by external forces (Wenger, 1998, p. 228). Pearce (2011) adopts the term "communities of play" to intentionally challenge the implied meaning that has been established with communities of practice. Pearce asserts that play can be described as a form of practice but, with regard to the formation of a community of practice and the potential for its activities to innovate, play and its complex relation to creativity deserves further definition and interpretation.

\section{THE VALUE OF PLAY AND CREATIVITY}

Creativity can be defined in relation to the relationship between the creative act and its recognition, such as the creation of "new or original ideas, insights, restructuring, inventions or artistic objects which are 
accepted by experts as being of scientific, aesthetic, social or technological value.” (Vernon, 1989, p 94.) In terms of the 'value' of creativity, it can be beneficial to consider the relationship between creativity and innovation, as these terms are often interchangeable yet can have two very different meanings. Bateson (2013, p.3) claims that "creativity is displayed when an individual develops a novel form of behavior or novel idea, regardless of its practical uptake and subsequent applications. Innovation means implementing a novel form of behavior or an idea in order to obtain a practical benefit which is then adopted by others." Creativity can lead to innovation, but creativity and innovation can also exist separate to one another.

Creativity and play, like creativity and innovation, have close ties to one another. Play for example, has been proven to have a positive effect on the creativity of children (Howard-Jones, Taylor and Sutton, 2002). Kline, Dyer-Witheford \& De Peuter (2003) identify the positive contribution that play can provide in the contexts of learning and formal education, recognising that "different forms of play permit varying degrees of creativity and experimentation, as well as some questioning of social roles.” (p. 244) Russ (2015, P57) claims that play can be seen as a "window on the beginnings of the creative process." This close link between play and creativity can be attributed to the ability of play to aid the development of "cognitive, affective and personality processes involved in creativity. Cognitive processes such as divergent thinking, and affective processes such as affect-laden fantasy that occur in play, are expressed in play and develop through play experiences.” (Russ, 2015, P58)

Play has been recognized to defy definition (Sicart, 2014), however, the work of Caillois (1961) provides an exhaustive and robust classification of the different forms of play, categorising activities across four key concepts: agôn as competition and challenge, alea as chance, mimicry as role-playing and simulation, and ilinx as physical sensation and disorientation. These categorisations are further distinguished through 
Caillois' definition and application of paida and ludus, or unstructured and structured play.

Through the deconstruction of a century of play theories, Sutton-Smith (2009) contends that play is a varied and ambiguous concept that has been appropriated by different academic disciplines and analysed with a narrow focus or bias, that struggles to accurately represent the intangible qualities of play. Much of the work undertaken by theorists and sociologists exploring the concept of play is founded upon the concepts and theories proposed by Huizinga (1949) who states that play predates culture and is an activity that was not created by man. Huizinga argues that there is a close connection and purity of play within the arts of music, poetry, and dance, which is partly driven by the fact that they are usually bound to performance as opposed to being bound to objects, labour, and matter, as can be recognised in the "plastic arts" of architecture, sculpture, painting and ceramics. Huizinga stresses the importance of the relationship between play and the creation of objects "if therefore the play-element is to all appearances lacking in the execution of a work of plastic art, in the contemplation and enjoyment of it there is no scope for it whatever.” (p. 166)

Across other fields, play has been defined and interpreted as a wasteful or unproductive activity. McClelland (2007) explores the relationship of play and sport in a global context, arguing that play is a ludic activity that is wasteful of time, and that work is a serious activity that is productive in terms of time. This view, although clearly open to dispute, can be recognised as the type of assertion that can be misinterpreted, further compounding the issue that reduces society's ability to objectively view play as a productive and essential part of the creative process. Play and the state of being playful are crucial elements in the creation of games, which Fullerton (2014) expresses "is a challenging task, one that requires a playful approach but a systemic solution.” (p. 2) This indicates that there are moments within the design and development process that are more suited to either exploring playful methods or using play as a tool to drive production or enable creativity. Landry and Bianchini 
(1995) discuss creativity as a concept that has often been defined as being a feature of personality or a characteristic that is developed in an individual as part of their collective learning or lived experience. However, they claim that "genuine creativity involves thinking a problem afresh and from first principles; experimentation; originality, the capacity to rewrite rules; to be unconventional; to discover common threads amid the seemingly disparate; to look at situations laterally and with flexibility. These ways of thinking encourage innovation and generate new possibilities...emphasising the new, progress and continual change.” (p. 18) The qualities and values proposed in this statement can be oriented with modernism which challenged traditional ideals and embraced experimentation and exploration of process. Kester (2004) discusses such creative acts or interventions as being a key legacy of modernism whereby the conditions and situations of objects are disregarded with instead, a focus on the methods in which "aesthetic experience can challenge conventional perceptions...and systems of knowledge.” (p. 3)

\section{SPACES TO PLAY: CREATIVE HUBS, COLLECTIVES AND LANDSCAPE OF PRACTICE}

Crogan (2014) highlights how creative economy initiatives often fail to address or indeed include creativity as a core element, instead promoting models whereby the true emphasis rests on economic, legal, and infrastructural conditions that downplay the potential generation of cultural value. In response to such strategic oversights, Crogan identifies the potential role of creative hubs as a vehicle to facilitate creativity and play in the establishment and development of communities, and to drive innovation within the creative industries. Like communities of practice, creative hubs develop where there is a recognised shared interest or potential, and thus the landscape is fragmented internationally. The creative hub exists in many forms, from Government led initiatives such as the National Film Board of Canada (ONF-NFB, 2016), to large scale commercial initiatives such as MediaCity in the UK (Ball 2014), 


\section{ToDiGRA}

private and academically supported incubators for entrepreneurship such as Chicago's Entrepreneurial Hub for Digital Start Ups 1871 (1871 2016) through to independent arts collectives and collaborative workspaces including Watershed in the UK (Watershed, 2015), Bento Miso in Canada (Gamma Space Collaborative Studio, 2016) and Play, Collaborative Arts Venue in Los Angeles, USA (Play Collaborative Arts, 2016). Arts collectives and collaborative workspace, like creative hubs, are self-organised creative communities. However, these are usually driven by artistic, social or political intent with less economic motivation and thus can aim to be more experimental and disrupt "existing aesthetic formulas” through their practice (Cotter, 2016).

Creative hubs, much like communities of practice, require a pool of talent to support creativity and embed creative practice for future generations (Ball, 2014). Creative Industries tend to grow in clusters across the UK, and the development of areas with complementary skills (commercial, creative and academic) can develop strong network for creative and economic growth (Chapain et al., 2010). Universities are recognised as a source of emerging talent to fuel and support creative industries, and creative hubs often reference the cluster of commercial, academic, and creative skills as the core to their success (Ball, 2014, Wright, 2015). However, it is important that the role of universities can be recognised as extending beyond the development of talent and towards innovation, as the knowledge within research and academic staff can provide a disruptive element that questions practice and diversifies the collective environment for undertaking challenging, creative work. Creative hubs and universities can act as "context providers" for communities of practice (Kester, 2004). The context provider focuses on process and the creation of spaces within which conversation and participation can lead to the generation of innovation and creativity. In relation to this paper, the context provider could be seen as a facilitator who designs spaces and interventions within which a community of practice can flourish. 
Communities of practice can harness the potential within a creative hub to form an ecosystem that is held together by a collective sense of value, trust and the possession of abilities to resolve conflict. Process is central to the creation of such an ecosystem and must develop intuitively from inside the community itself (Wenger, 1998). Communities of practice often exist without such facilitation or support. However, it could be argued that within existing communities of practice - for example, small-scale videogame development - the ecosystem is polluted by an oversaturation of developers reproducing existing styles, structures, and mechanics of previously successful genres. Similarly the tools of game development compound this and can be identified as promoting a bias and dictating a specific way of working, conceptualising, and distributing games. Game engines, the software many developers use to build their games, have a distinct look and feel which can also result in an unintentional, generic look and feel across a spectrum of small, independent productions.

Such outcomes could be viewed as the stagnation of a community of practice. Support by a facilitator could help to disrupt process and inspire new processes within a community. For example, the application of constraints, such as proposed by Norman (1998) could be used to design activities to challenge a community's existing processes. Stokes (2005, p.7) believes constraints upon creativity are "barriers that lead to breakthroughs" and can promote novel responses within constrained creativity. Laurel (2014, p.130) supports this view: "Limitations...paradoxically increase one's imaginative power by reducing the number of open possibilities.” A context provider could support innovation through playful application of constraints to trigger innovation. However, challenging existing meaning within a community can be a volatile process, and context providers must recognise that "learning cannot be designed. Ultimately, it belongs to the realm of experience and practice. It follows the negotiation of meaning; it moves on its own terms.” (Wenger, 1998). 
Disruption could also occur by traversing the landscape of practice to collaborate across disciplinary boundaries (Hutchinson et al., 2015). The collaboration of individuals from different disciplinary backgrounds can lead to innovation and creativity within and across disciplines. This process can present issues, as each individual draws from the history of their field of practice which "creates a boundary with those who do not share this history.” (Wenger-Trayner, 2015) Therefore, terminology, interpretation, and perspectives are coloured by the background and experience of the individual. There is potential for cross boundary playful experimentation to address issues of varying histories and perhaps to progress into the development of new shared assumptions upon which innovation could be based. However, the communities coming together at a boundary upon the landscape of practice must recognise the value in the perspectives of the other disciplines and that the knowledge present within each community may or may not be compatible.

\section{METHODS}

In order to examine the feasibility of play as a method for the development of a community of practice and for fostering innovation within creative practice, two case studies will be presented. Each case study will examine the potential community and will evaluate the use of play as a method to aid the development of shared language, and more specifically to explore the use of designed constraints within structured play as a motivator of creativity and innovation. Each case study took the form of a workshop series and uses qualitative data gathered through open observation of participants within the workshops. The first, Development Cultures, was a six-month workshop series that brought together practitioners, academics and students within the discipline of videogames. The second case study, Performance and Play was a weeklong intensive workshop that brought together practitioners and academics from the performing arts and videogames to explore the application of practice and process across disciplinary boundaries. 


\section{CASE STUDY ONE: DEVELOPMENT CULTURES 2014}

Development cultures was a six-month collaborative project which brought together industry practitioners and academics from the field of videogames to share practice, develop relationships, and stimulate discussion around the process, purpose, and potential of experimental game design. In the design of events (Figure 1), the context providers sought to build trust, challenge assumptions, explore routes for innovation and collaboration through definition of shared intent, and promote experimentation through playful interaction. The initial workshop in April 2014 was made up of twenty-three developers and academics. Over the course of the project, the participant group expanded to forty-six for the final workshop in July 2014.

Two practical creation events (or jams) were preceded by reflective seminars where participants shared their personal experiences of game design and development. Jams were identified as ideal experimental vehicles for this project because game jams are known for their ability to foster creativity (Guevara-Villalobos, 2011), develop new skills and relationships (Reng et al., 2013), and have potential to disrupt existing practice (Locke et al., 2015).

Within the reflective seminars, the group was able to begin the identification of themes across individual aspirations because all participants drew from an existing understanding of the domain. These seminars aimed to build a collective understanding of creative intent to aid the formation of a community of practice. Throughout both seminars, participants evaluated their own and others' processes and questioned conventions. Such exploration and re-definition of the collective understanding aided connections within the community and eased the introduction of new members in the later stages of the project. The impact on practice was most evident in the Analogue to Digital and Jump Jam events. 


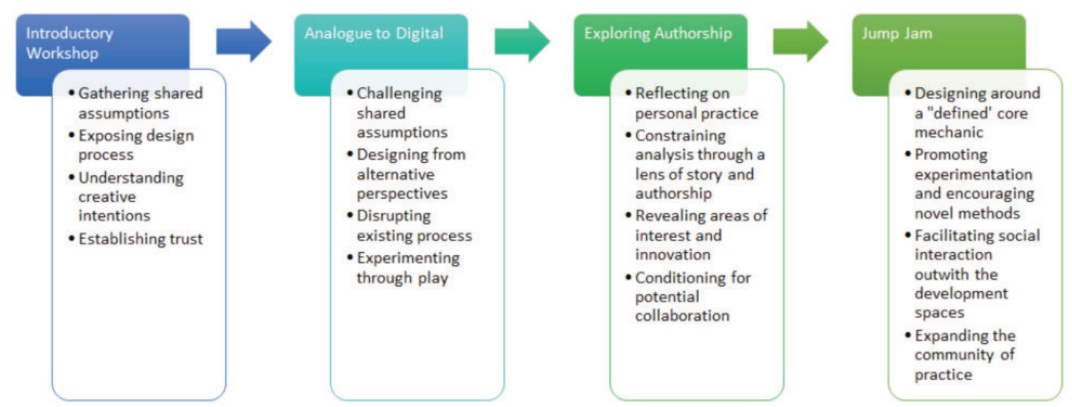

Figure 1: This figure details the goals of playful interaction within each event that aimed at each stage to support, develop and challenge innovation and creativity in a developing community of practice.

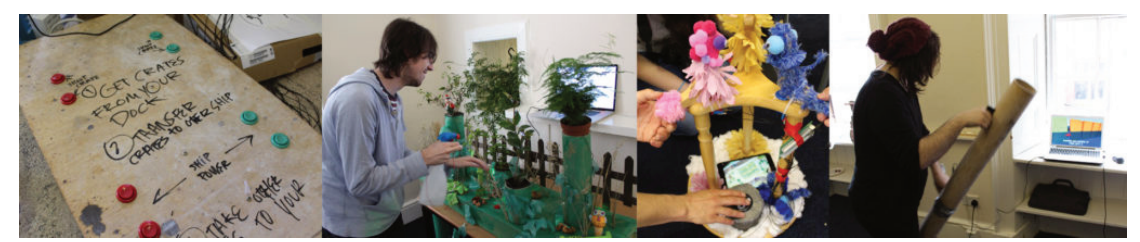

Figure 2: Photographs taken during the event of a selection of the experimental controllers and games.

Analogue to Digital: Designing from a New Perspective

The Analogue to Digital workshop aimed to disrupt thinking about interaction with a game to encourage experimentation and creativity. The event challenged participants to explore novel methods for user interaction, utilising found objects that could be re-constructed into custom input devices for games (Figure 2). Teams were tasked with devising and developing a game prototype (along with a bespoke custom controller) and were provided with analogue arcade components such as buttons, micro-switches, joysticks and wires.

Self-organisation of teams allowed for like-minded participants to group together to create work. In some cases, teams were formed by a company with no external input, which ensured ownership remained within the 
company whereas other teams were formed across companies and academia enabling knowledge exchange.

The five-hour workshop led to the compression of typical development, design and planning phases and thus once an idea was formed, the designs were iterated upon only as challenges arose. Short time frames are a typical attribute of the game jam (Goddard et al., 2015) with many jams lasting for only 12, 24 or 48 hours. In this case, the time frame was very heavily compressed, which led to further disruption of conceptual and developmental processes. The intimate and unfamiliar workspace fostered an attitude of open collaboration within and across teams. The event focused on design from the player's perspective rather than for existing controllers challenging logical conventions of game development. This altered participant focus with a third of the participants claiming that they were required to foster the co-creation of new processes for design and implementation. The innovative potential of input devices and how they can shape player experience (for better or worse) was a clear outcome of the event and many of the participants expressed a wish to continue this kind of development beyond the workshop.

\section{Experimental Game Jam: The Jump Jam}

The Development Cultures project closed with a two-day twelve-hour game jam where industry professionals, academics and students formed teams to create experimental games around the theme of 'the jump'. The theme of the jam was promoted prior to participant arrival. Typically game jams do not reveal their theme prior to arrival of participants, and one individual commented that the disruption of this tradition "allowed us to collaborate and share ideas in advance, building an atmosphere in groups and on social media before the jam began.” This event was designed to foster experimentation and facilitate community development through openness and play, thus, social events were scheduled throughout in the form of an introductory meet and greet, a social mixing event on the first evening and an awards ceremony 


\section{ToDiGRA}

at the end. The guest list was curated to ensure a proportionate mix of independent developers, students and academics that expanded participation beyond the existing community of practice of the project, inviting fresh perspectives and diversity into the community. The expansion of the community was successful in terms of sharing experience and networking, however, most teams were formed by individuals with existing relationships, and only one team was formed by individuals with no previous experience of working together. There was limited knowledge transfer in teams that had previously worked together, as working practices were a known factor, however, known relationships within a group can help the team to achieve 'group flow' which is central “to foster improvised innovation.” (Sawyer, 2008)

The designed inclusion of social activity into the event may have further facilitated sharing of experience and development of relationships. Across teams, community development also occurred informally during breaks, in social events or via on-line resources such as Facebook or Twitter. The use of social media was promoted, (using \#AGLjam) for sharing ideas and group problem solving. Participants posted positive comments relating to the experience, development of relationships and range of creativity in prototypes (Hunt 2014). Many final prototypes have been posted online and Storify articles were created to document individual and jam-wide activity (Abertay GameLab, 2014, Hidden Armada, 2014). The breadth of engagement with social media indicates that it serves an important role in sharing experience with the game development community beyond those directly involved in the event itself.

The game jam produced twelve game prototypes, many of which utilised technology, space, and interaction in novel ways (Figure 3). The playful structure of the game jam also influenced the future commercial activities of some of the participants. New working partnerships were formed, and the potential of new intellectual property was recognised. This is evident by the demonstration of one prototype at a major UK games consumer event (Eurogamer, 2014) and the development of 
another into a full-scale game for commercial release on Xbox One and Steam (Jump Stars, 2016).

\section{CASE STUDY TWO: PERFORMANCE AND PLAY 2015}

Performance and Play was a weeklong intensive workshop hosted by the Dundee Repertory Theatre in February 2015, which brought together thirty-two creatives from performing arts and game development to explore the connections between performance and play.Figure 4 goes here

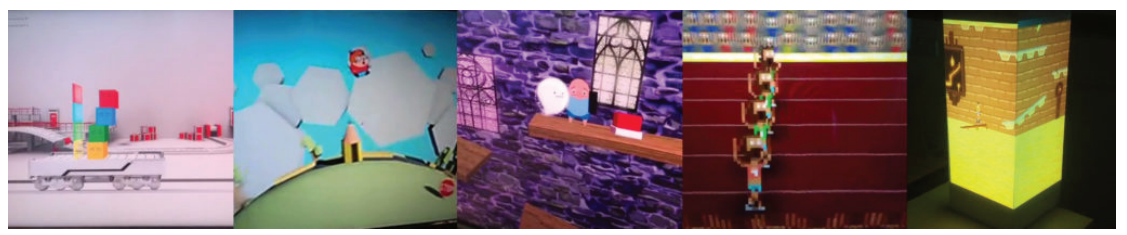

Figure 3: Screenshots from games produced at the jam from left to right: "The Boy who Couldn't", a Leap Motion game where players have to bounce the character to avoid obstacles; "Boo", a scaring game which uses the player's voice as an input; "Accelerunner", a four player running simulator; "Phoenix Down", a three player tower climbing game on a real tower.
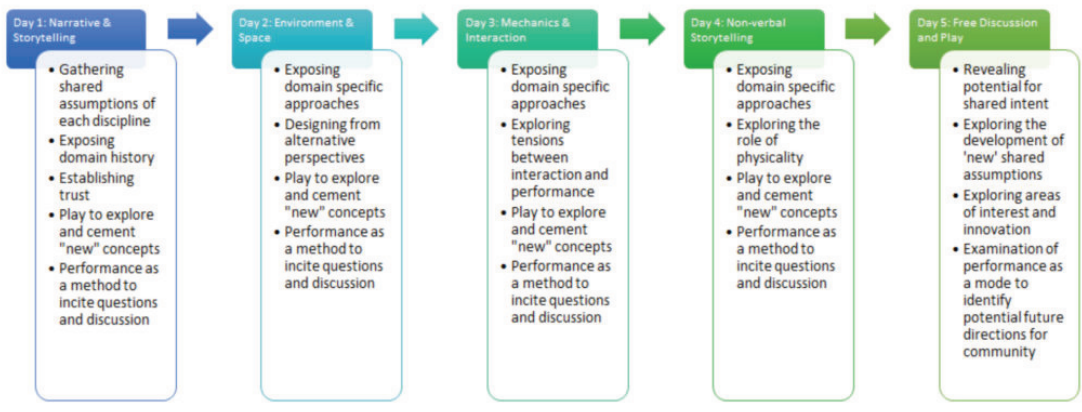

Figure 4: This figure details the goals of each day of the workshop which aimed to develop trust, a shared understanding and innovation through play in a developing community of practice.

From the performing arts, participants included actors, artistic directors, creative contributors and choreographers (referred to as 'performers' 


\section{ToDiGRA}

for the purposes of discussion) and within the field of videogames, collaborators included artists, game designers, sound designers and academics (referred to as 'gamers' for the purposes of discussion).

This project benefitted from an intensive development timeframe and shared intent, as the event was designed with an existing recognition by the participants of the potential benefits to their individual community of practice in working with other communities. The first day focused on developing trust by defining participants' hopes for the week and through definition of domain-specific terms to form a basis of knowledge for the community. Each day of the workshop purposefully followed a predictable format; domain specific knowledge was shared and discussed each morning, and each afternoon this information was used to structure playful experimentation and to incite further discussion (Figure 4).

Structured play took the form of roleplaying, simulation, and experimental collaboration within given design constraints. Participants worked in small randomly-assigned groups throughout to ensure a breadth of cross-domain interaction. Time was allocated at the end of each day for groups to 'perform' the outcomes of their experimentation and to question, identify and explore tensions at the boundary between the communities. The format enabled knowledge transfer between groups and encouraged input from all participants to immerse each discipline within the world of the other. The final day leveraged the developing shared understanding to look into possible collaborations and future work through debate, discussion, and play around digitallymediated art production.

\section{Sharing Histories}

On the first day of the workshop, each participant was asked to write three hopes for the week (anonymously) and to post these to the wall. This framed individual goals and formed a foundation for discussion. As the participants had come from a range of communities of practice, it was 
important for introductions and discussion of intentions to take place, to clarify goals, pre-conceptions and introduce language from each field (Wenger-Trayner, 2015).

The identified hopes for the week demonstrate five key themes: the creation of work; networking to form meaningful collaborations; breaking down boundaries between communities of practice; gaining knowledge to expand personal practice; and looking for inspiration. The most prevalent of these themes was the hope that boundaries between communities of practice could be broken down. This permeated through each of the other expressed hopes for the week and seemed important to the achievement of personal agendas. "Mutual understanding of craft", being "brave and sit[ting] with the awkward difference of practice" and "being less afraid of technology" are three of fifteen such explicit expressions from participants. These results verify that the project tapped into an existing "potential” community (Wenger-Trayner, 2015), as the group expressed willingness to learn from other communities of practice with a hope to form collaborations. Discussions around interactive theatre raised a concern that interactivity might subsume theatre as a standalone practice. The workshop valued each form in its own right and aimed to explore spaces of possibility at the boundaries of each practice. The workshop's designed time for open discussion helped the group to form a shared understanding that it may be possible to bring together interactivity and performance to form a new community of practice, which does not subsume or replace traditional approaches to theatre, dance or gaming. Time for discussion within the workshop schedule was key to the definition of such parameters.

\section{Play and Developing Community}

Play became core to the identification of issues across practices. Each afternoon, playful tasks were assigned to randomly-generated groups of participants to encourage experimentation with the theme of the day. Outcomes of experimentation were performed to the entire community at the end of each session, to spark discussion and knowledge sharing. 
Chance played a role not only in team generation but also in many of the experimental outcomes. On the first day, one of six small groups was formed by performers only (with no gamers) due to a chance formation of groupings. The designated task required the generation of an interactive narrative but the group had no previous experience of interactive narrative generation and thus utilised logical constraints and trial and error to create their performance. The final 'playable' performance (a playable performance is where an audience interacts with performers to shape the progression of a performance, perhaps through physical interaction or verbal direction) demonstrated innovation and creativity in the application of interactivity to a narrative structure, but the stories produced made very little narrative sense. In this case, chance allowed for novelty in the creative process but the lack of knowledge of interactive design led to gaps in understanding and suggests a need for diversity in groupings across communities of practice.

The application of competition and challenge within playful experimentation highlighted innovative potential. On day three, teams of two (performer and gamer) were tasked with the reinterpretation of existing board games focusing upon interaction and mechanics. The design process carried out by each team was very physical, with participants intuitively choosing to disrupt sedentary conventions of board games, challenging the physical, semantic, cultural and logical constraints of the given games through their experimental reinterpretation (Norman, 1998). Some participants imagined the removal of physical constraints such as gravity on the creation of a new game, and others reinterpreted jigsaws so that players had to run from one scattered piece to the next to win the game. Participants' familiarity with the board games inspired their challenge of conventions and led to competition and challenge underpinning the design of revised versions of the games. All of the eight games designed by teams had a win state and were multiplayer, relying upon competition between players to motivate progress. The basis of play upon competition within this activity differed greatly to the forms of play within all of the other outcomes of the week, where instead, groups utilized mimicry, physical 
sensation, disorientation and chance. One unifying factor across all of the playable performances made during the workshop was that challenge was important, but competition less so. Instead, many of the outcomes required the player or audience member to interact and collaborate with fellow players to "solve" the performance.

In another task, play helped to uncover previously unspecified tensions between performance and games. On the final day, randomly-generated teams had to create a playable performance. One team tasked the audience to move through a space, two at a time - each in their own unique play/performance space. They became active participants required to collaborate with one another to solve the puzzle of the performance. The presentation of this performance to the community identified a need for many performers within the 'play' space to create an experience for only two audience members at a time. This sparked discussions around tensions in audience roles and commercial viability in interactive performance. In games, the experience tends to be one-toone, where the player controls the unfolding of the interactive experience at their own pace. Within performing arts on the other hand the performer performs for a pre-defined length of time to an audience of many. The experimentation within the workshop identified a tension between the one-to-one system of games and the one-to-many system of performance. Play allowed the group to identify, question and explore the creative, conceptual, operational, and commercial issues around this tension.

\section{Developing a New Community}

Performance and Play finished with participants anonymously posting their goals on a wall for future discussion. This activity made it clear that a shared creative intent developed over the course of the week. None of the participants identified exploration of boundaries as a goal moving forward, but instead suggested the creative experimentation across performing arts and videogames. The responses can be organised into three categories: intent to experiment practically; intent to create work 
around a designed theme; and intent to create specific artwork. Fourteen specific ideas for playable performances which cross digital and physical boundaries have been proposed, a further fourteen themes have been suggested to shape experimental development, and five participants generally suggested further practical activity in the field.

\section{CREATIVITY AND CREATIVE COMMUNITIES - A THEORETICAL FRAMEWORK}

The case studies present a range of creative 'interventions' which can help the formation of a potential community of practice into an active community of practice. They suggest that structured play and designed constraints to disrupt assumptions can inspire creativity and innovation. The role of the context provider is to recognise potential communities and to support their development by creating an environment where creativity can flourish. We propose that, when designing such interventions, there are four key stages that a context provider must consider in order to fully support a potential community of practice (Figure 5). 


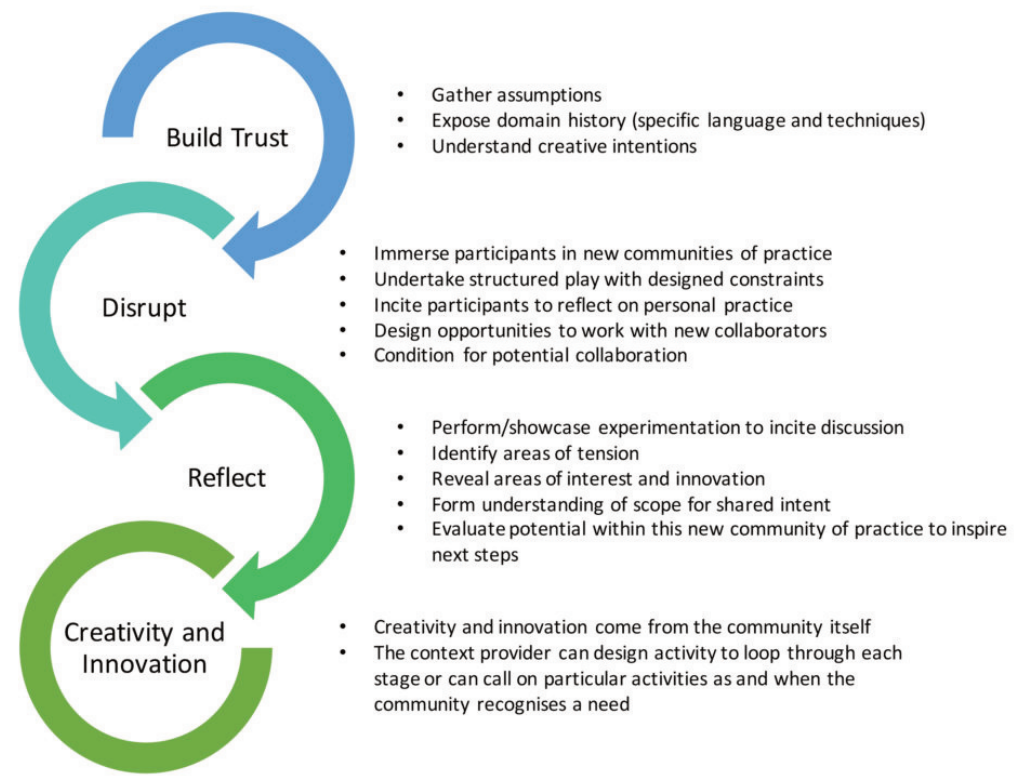

Figure 5: A framework for the context provider.

The first stage is the creation of trust within the community. All participants must find an equal footing on which to develop a new community, thus individual assumptions must be identified and explored as a group. Anonymity in initially presenting ideas (through posting thoughts to a wall) helps to form a basis for open discussion in a newlyformed community. Once confidence within the group is developed at this early stage, it is possible to invite participants to more openly express their thoughts, experiences and perspectives. Domain specific history, terms and techniques should be defined at this stage to form a base understanding from which outcomes can develop.

Stage two requires practical experimentation to inspire creativity and then the disruption of process through structured play and constraints. The case studies suggest that new collaborations help knowledge exchange and can prepare the community for collaboration beyond experimentation. However, there is no 'perfect' way to organise new 
collaborations to ensure creative endeavor; within the case studies, both randomly assigned teams and self-organised teams produced mixed results. The context provider must therefore clearly define the goals of experimentation and the design constraints, and then interpret the relationships within the community to determine an appropriate group forming technique.

Stage three requires time and space for the entire community to experience and interact with experiments from stage two. The community should explore and discuss the possibilities and tensions presented by this work. Experimentation acts as a catalyst to reveal potential, form a shared understanding and inspire future work.

Stage four sees creativity and innovation emerge from inside the community. The context provider must design opportunities for the group to form their own concrete plan of action beyond the workshop events. Such plans help to motivate further interaction within the community (out with physical space) and provide targets for the group to work towards. Follow-up sessions (some months after the original series) are proposed as a useful tool to motivate activity and ensure the experiences of small (possibly self-formed) groups within the community are shared with the entire community. This stage would lead to (or be the dissemination of learning from) large-scale outcomes created by the community, representing the developed shared vision of the community.

In conclusion, we propose that the framework presented within this research relies upon a context provider as an individual or organisation that recognises the need for and designs a space to support creative endeavor within a potential community of practice. The context provider motivates or disrupts practice through the design of conditions and constraints to allow communities to question competences, shared assumptions and trigger creativity. It is not possible to design a community of practice; however, it is possible to design spaces and 
activities within which communities can foster innovation and creativity for themselves.

\section{ACKNOWLEDGMENTS}

We thank all of the participants in the Development Cultures and Play and Performance projects for their participation in the event and in support of this research. We gratefully acknowledge the participation and support of the National Theatre of Scotland, Dundee Repertory Theatre, Scottish Dance Theatre, Lucky Frame, Secret Experiment, Quartic Llama, Guerrilla Tea, Ninja Kiwi, Hidden Armada and Abertay University. We also gratefully acknowledge funding support from Abertay University to facilitate the Development Cultures project.

\section{BIBLIOGRAPHY}

1871 (2016) About Us. Website. Available at http://www.1871.com/ about-1871/ (Accessed April 2016)

AbertayGameLab. (2014) \#AGLjam. Website. Available at https://storify.com/AbertayGameLab/

agljam?utm_source=story\&utm_media=storypage\&utm_content=relate d (accessed August 2015)

Ball, K. (2014) The Social and Cultural Impacts of Regeneration on Particular Locations in Manchester City and Salford Quays. Available at http://www.thebuildingfuturesgroup.com/wp-content/uploads/2014/07/ Student-Ambassadors-Report-Katherine-Ball.pdf (accessed August 2015)

Bateson, P. (2013) Play, Playfulness, Creativity and Innovation. Cambridge University Press. 
Caillois, R. (1961) Man, Play and Games. University of Illinois Press.

Chapain, C. Cooke, P., De Propris, L., MacNeill, S. \& Mateos-Garcia, J. (2010) Creative Clusters and Innovation: Putting Creativity on the Map. Available at https://www.nesta.org.uk/sites/default/files/ creative_clusters_and_innovation.pdf (accessed August 2015)

Cotter, H. (2006) The Collective Conscious. Available at http://www.nytimes.com/2006/03/05/arts/design/ 05cott.html?pagewanted=all\&_r=0 (accessed August 2015)

Creative Scotland. (2014). Unlocking Potential, Embracing Ambition: A Shared Plan for the Arts, Screen and Creative Industries. Available at http://www.creativescotland.com/_data/assets/pdf_file/0012/25500/ Creative-Scotland-10-Year-Plan-2014-2024-v1-2.pdf (accessed August 2015)

Crecente, B. (2014) As game players diversify, developers start to rethink the stars of their games. Available at http:/www.polygon.com/ 2014/6/23/5834628/women-in-video-games-heroines-e3-2014 (accessed August 2015)

Crogan, P. (2014) Mapping the Collective: Potentials of Indie Game Collaboration. Presentation. Digital Cultures Research Centre. Bristol, England.

Csikszentmihalyi, M. (1996) Creativity: Flow and the Psychology of Discovery and Invention. New York, Harper Collins.

Dixon, S. (2007) Digital Performance: A History of New Media in Theatre, Dance, Performance Art and Installation. MIT Press, Cambridge, Massachusetts.

Eurogamer. (2014) Accelerunner - Eurogamer Let’s Play - EGX 2014. Video. Available at https://www.youtube.com/watch?v=O4X-hsPEWLY (accessed September 2015) 
Flanagan, M. (2009) Critical Play: Radical Game Design. The MIT Press, Cambridge.

Fullerton, T. (2014) Game Design Workshop: A Playcentric Approach to Creating Innovative Games. CRC Press, Florida.

Gamma Space Collaborative Studio (2016) What it's All About. Website. Available at: https://bentomiso.com/about (Accessed April 2016)

Goddard, W., Byrne, R. \& Mueller, F. (2014) Playful Game Jams: Guidelines for Designed Outcomes In IE2014 Proceedings of the 2014 Conference on Interactive Entertainment (IE2014 2014) pp. 1 - 10.

Guevara-Villalobos (2011) Cultures of independent game production: Examining the relationship between community and labour.

In Proceedings of DiGRA 2011 Conference: Think Design Play. (DiGRA 2011)

Hidden Armada. (2014) AGLjam Game Pheonix Down. Website. Available at https://storify.com/HiddenArmada/agljam-gamephoenixdown (accessed August 2015)

Howard-Jones, P., Taylor, J., and Sutton, L. 2002. “The Effect of Play on the Creativity of Young Children During Subsequent Activity” in Early Child Development and Care 172 - 4, pp. 323-328.

Huizinga, J. (1949) Homo Ludens: A Study of the Play-Element in Culture. Routledge and Kegan Paul, London.

Hunt, N. (2014) "Had such an awesome time at \#AGLJam! Met lovely people, played amazing games and started a Hyper-Realistic revolution with @AlanZucconi!”. 27 July, 2014. Tweet. Available at https://twitter.com/nicollhunt/status/493416608468316160 (accessed August 2015) 
Hutchinson, S., Fenton-O’Creevy, M., Goodliff, G., Edwards, D., Hartnett, L., Holti, R., Mackay, E., McKeogh, S., Sansoyer, P., Way, L. (2015) "Introduction: An Invitation to a Conversation” in Learning in landscapes of practice: Boundaries, identity and knowledgeability in Practice-Based Learning. Wenger-Trayner, E. Fenton-O’Creevy, M. Hutchinson, S., Kubiak, C. Wenger-Trayner, B (eds.). Routledge, London, UK, pp. 01-09.

Jenkins, H. (2005) "Games, the New Lively Art" in Handbook of Computer Game Studies. Goldstein, J., \& Raessens, J. (eds.). MIT Press, Cambridge, Massachusetts, pp. 175-192.

Jump Stars (2016) Website. Available at http://www.jumpstarsgame.com (accessed December 2015)

Kester, G. (2004) Conversation Pieces: Community and Communication in Modern Art. University of California Press, Berkeley.

Kline, S., Dyer-Witheford, N. \& De Peuter, G. (2003) Digital Play, The Interaction of Technology, Culture, and Marketing. McGill-Queen's University Press, Montreal.

Kwastek, K. (2013) Aesthetics of Interaction in Digital Art. MIT Press, Cambridge, Massachusetts.

Landry, C., and F. Bianchini. (1995) The Creative City. Demos, London.

Laurel, B. (2014) Computers As Theatre. (2nd. ed.).: Addison-Wesley, New Jersey.

Locke, R., Parker, L., Galloway, D. \& Sloan, R. (2015) The Game Jam Movement: Disruption, Performance and Artwork. In Workshop Proceedings of the 10th International Conference on the Foundations of Digital Games. (FDG 2015).

McClelland, J. (2007) Body and Mind: Sport in Europe from the Roman Empire to the Renaissance. Routledge, London. 
Norman, D. (1998) The Design of Everyday Things. MIT Press, London.

O’Grady, A. (2011) “Interactivity: Functions and Risks” in Performance Perspectives: A Critical Introduction. Pitches, J. Popat, S. (eds.). Palgrave Macmillan, Hampshire, UK, pp. 165-172.

ONF-NFB (2016) Mission and Highlights. Website. Available at: http://onf-nfb.gc.ca/en/about-the-nfb/organization/mandate/ (accessed April 2016)

Pearce, C. (2011) Communities of Play: Emergent Cultures in Multiplayer Games and Virtual Worlds. MIT Press. Cambridge, Massachusetts.

Play Collaborative Arts (2016) We're on a Mission to Play. Website. Available at: http://www.artsatplay.com/\#!mission/c1xtw (accessed April 2016)

Practice from Different Game Jams in Workshop Proceedings of the 10th International Conference on the Foundations of Digital Games. (FDG 2015).

Reng, L., Schoenau-Fog, H \& Kofoed, L. (2013) The Motivational Power of Game Communities - Engaged through Game Jamming in Workshop Proceedings of the 8th International Conference on the Foundations of Digital Games. (FDG 2013).

Russ, S. W. (2015) "Play, Affect and Creativity: Theory and Research" in Affect, Creative Experience, and Psychological Adjustment. Russ, S., W. (eds.) Taylor and Francis, Philadelphia, USA, pp. 57-76.

Sawyer, K. (2008) Group Genius: The Creative Power of Collaboration. Basic Books, New York.

Salen, K. \& Zimmerman, E. (2004) Rules of Play: Game Design Fundamentals. MIT Press, London. 
Schein, E. H. (2010) Organizational Culture and Leadership. John Wiley \& Sons, San Francisco, CA.

Shyba, L. M. (2007) The Spontaneous Playfulness of Creativity: Lessons from Interactive Theatre for Digital Games in Proceedings of the 2007 DiGRA International Conference: Situated Play. (DiGRA 2007), pp. 779-782.

Sicart, M. (2014) Play Matters. The MIT Press, London.

Sternberg, R. J., and Lubard, T. I. (1999) “The Concept of Creativity: Prospects and Paradigms” in Handbook of Creativity. Sternberg, R., J. (eds.), pp. $3-14$.

Stokes, P. (2005) Creativity from Constraints: The Psychology of Breakthrough. Springer, New York.

Sutton-Smith, B. (2009) The Ambiguity of Play. Harvard University Press.

Vernon, PE. (1989). “The Nature-Nurture Problem in Creativity” in Handbook of . Glover, J. A., Ronning R. R., and Reynolds, C.R. (eds.) Springer US, pp. 93-110.

Watershed. (2015) About Us. Website. Available at http://www.watershed.co.uk/about/about-us (accessed August 2015)

Wenger, E. (1998) Communities of Practice: Learning, Meaning and Identity. Cambridge University Press.

Wenger, E., McDermott, R.A. \& Snyder, W. (2002) Cultivating Communities of Practice: A Guide to Managing Knowledge. Harvard Business Press, Boston.

Wenger-Trayner, E. Wenger-Trayner, B. (2015) "Learning in a landscape of Practice: a Framework" in Learning in Landscapes of Practice: Boundaries, identity and knowledgeability in Practice-Based 
Learning. Wenger-Trayner, E., Fenton-O’Creevy, M. Hutchinson, S., Kubiak, C. Wenger-Trayner, B. (eds.). Routledge, London, UK, pp. 13-29.

Wright, S. (2015) DShed: Past, Present \& Future. Available at http://www.watershed.co.uk/dshed/articles/dshed-past-present-future (accessed August 2015)

Wood, J. (2011) “Gaming and Performance: narrative and Identity” in Performance Perspectives: A Critical Introduction. Pitches, J. Popat, S. (eds.). Palgrave Macmillan, Hampshire, UK, pp. 115-122. 